\title{
The Endogenous Economy: 'Real' Economic Conditions, Subjective Economic Evaluations and Government Support ${ }^{1}$
}

Cees van der Eijk ${ }^{\mathrm{a}},{ }_{\mathrm{d}}$ Mark Franklin ${ }^{\mathrm{b}}$, Froukje Demant ${ }^{\mathrm{c}}$ and Wouter van der Brug ${ }^{d}$

${ }^{a}$ Social Sciences Methods and Data Institute, University of Nottingham, Nottingham NG7 2RD, UK.

E-mail: ceesvandereijk@nottingham.ac.uk

${ }^{\mathrm{b}}$ Department of Political and Social Science, European University Institute, 50016 San Domenico di Fiesole, Italy.

E-mail: Mark.Franklin@EUI.eu

${ }^{\mathrm{c}}$ Institute for Migration and Ethnic Studies, University of Amsterdam, 1012 DL Amsterdam, The Netherlands

${ }^{\mathrm{d}}$ Department of Communication Science, University of Amsterdam, 1012 CX Amsterdam, The Netherlands

Conventional wisdom holds that the state of the economy is closely linked to the outcomes of elections: incumbent governments tend to be rewarded for good economic times and punished for bad ones. It has been suggested that the 'subjective economy' - people's assessments of the state of the economy — links actual economic conditions to support for the government. Indicators of such assessments are therefore frequently included in voter surveys. Such subjective information has been criticized, however, as being endogenous: being caused by rather than a cause of vote choice. The purpose of this paper is to assess the relevance of the subjective economy for linking objective economic conditions and support for the government at the individual level. To this end, we specify and estimate a series of rivaling causal models, and compare them in terms of fit and parsimony. We find unambiguous support for the endogeneity interpretation of the subjective economy, which implies that it cannot play a sensible role in the causal elaboration of economic voting models.

Acta Politica (2007) 42, 1-22. doi:10.1057/palgrave.ap.5500172

Keywords: economic voting; subjective economy; endogeneity; EU-countries

\section{Does the Economy Affect Government Support? - the Nature of the Problem}

In politics and political science alike, conventional wisdom holds that the state of the economy is closely linked to the outcomes of elections: incumbent governments tend to be rewarded for good economic times and punished for 
bad ones (Tufte, 1976; Chrystal and Alt, 1981; Hibbs, 1982; Fair, 1988; LewisBeck, 1988; Markus, 1988, 1992; Erikson, 1989; MacKuen et al., 1992; Powell and Whitten, 1993; Whitten and Palmer, 1999; Nadeau and Lewis-Beck, 2001; Dorussen and Taylor, 2002). Bill Clinton turned this conventional wisdom into a cliché when, as a candidate in the 1992 American presidential election, he had his campaign staff put up a banner that hung across their campaign headquarters emblazoned with the words 'It's the economy, stupid!' This proposition has been supported by a wealth of academic research, particularly at the aggregate level. Yet, the individual-level mechanism that generates the observed relationship between economic conditions and electoral outcomes remains largely obscure, fuelling concerns that the aggregate-level findings may be artifactual.

The problem arises because scholarly research regarding the electoral consequences of the economy is of two kinds. One tradition relies on aggregate data. Vote shares or approval ratings of the incumbent government over time are regressed on economic conditions such as growth in GDP, inflation and unemployment. By and large, these analyses find that governments are 'rewarded' for good economic conditions and 'punished' for bad ones. But any empirical relationship that is established in this way need not reflect a concomitant individual-level relationship, as has more than once been pointed out (Kramer, 1983; Wlezien et al., 1997). Government vote shares could correlate with economic conditions because of common antecedent factors, or because of any number of aggregation artefacts. To dispel doubts about the spuriousness of these relationships, it is necessary to demonstrate their existence at the level of individual voters. And that is exactly what the second tradition of economic voting studies attempts to do. Survey data are used to model the effects of economic conditions on individual voters' preferences and choices. ${ }^{3}$ The problem with this approach, however, is that 'the economy' is a contextual phenomenon that does not vary between respondents, and that therefore cannot be used to explain differences in the preferences and choices of individuals that are observed in a single survey. ${ }^{4}$ In principle, this problem can be overcome by pooling many different surveys, each conducted in different economic circumstances, thus generating the variation that is necessary for regressing individual-level preferences and choices on economic conditions. The demands of this approach in terms of data comparability are daunting, however. ${ }^{5}$ As a consequence, it has seldom been practiced (but see Markus, 1988, 1992; Nadeau and Lewis-Beck, 2001; Van der Brug et al., 2007). The survey approach to economic voting has traditionally used a different solution to this problem. It has become commonplace to ask respondents about their views regarding the state of the economy. ${ }^{6}$ These subjective assessments do provide the necessary variation to serve as explanatory factors for voters' choices, but it is obvious that this variation 
cannot be a reflection of the singular context that is common to the respondents from a single survey.

The aggregate and the individual-level approaches to the study of economic voting are thus not really linking up. Aggregate-level analyses run the risk of not reflecting individual-level relationships; the individual-level approach based on the subjective economy cannot reflect the effects of the 'real' economy. Yet, it is conceivable that subjective assessments of economic conditions do reflect actual economic conditions, if only on average. This would be of no help as long as analyses were conducted for a single survey, but it would raise the possibility of employing surveys from multiple contexts, each with its unique economic conditions, and studying them in conjunction.

The relevance of subjective indicators of the economy has been questioned on other grounds as well. It has been argued that subjective assessments of the economy risk are being contaminated by the very phenomenon they are meant to explain: support for the government (Bartels, 1996; Wlezien et al., 1997; Duch and Palmer, 2002; Zaller, 2005). This so-called endogeneity problem would vitiate attempts to use indicators of the subjective economy to specify the causal mechanism that links real economic conditions to government support.

The purpose of this paper is to investigate whether or not the subjective economy can at the individual level be used to link objective economic indicators to government support, as is commonly done in the economic voting literature. This question contains two components. First, does the subjective economy (when assessed across different economic contexts) reflect the real economy? Second, if so, does the subjective economy affect government support? The means for addressing these questions empirically is provided by a unique set of highly comparable surveys that have been conducted in different economic conditions, and that contain information on subjective economic assessments and government support.

\section{Elaborating the Research Question}

The extant literature about economic voting focuses on two different kinds of dependent variables: government popularity on the one hand (e.g. approval of government performance) and vote choice on the other. In much of the economic voting literature, the distinction between these two phenomena is considered to be of little relevance, and both are often subsumed under the 'VP-function', where $\mathrm{P}$ refers to popularity and V to vote (Lewis-Beck and Paldam, 2000, 114, Table 1). Recently, however, evidence has accumulated that the $\mathrm{P}$ (opularity)-function behaves quite differently from the V(ote)-function (cf. Paldam and Nannestad, 2000, 390), in spite of strong empirical relationships between popularity and vote choice. In order to link up with both streams 
in the economic voting literature, we include in our model indicators of the P-domain as well as of the V-domain.

The most common way to conceptualize the impact of economic conditions is that governments are rewarded or punished for economic conditions that developed under their stewardship. It is therefore commonplace to define the dependent variable(s) in terms of the distinction between government and opposition. In our analyses, we follow this tradition in order to maximize comparability of our results with the findings reported in the literature. We will discuss some of the implications of the use of this dichotomy in the concluding section of this article.

We do not come to this research with specific hypotheses in mind. Rather, we want to assess the relative merits of rivaling views about the value of indicators in the subjective economy domain. One perspective is that subjective perceptions of the economy can sensibly be used when attempting to model the impact of the economy on government popularity or government vote shares. This view is (usually implicitly) held by analysts who use these subjective assessments as independent variables to explain government approval or voting for the government (e.g. Kinder and Kiewiet, 1979; Fiorina, 1981; Lewis-Beck, 1988; Middendorp and Kolkhuis Tanke, 1990; Nannestad and Paldam, 1997, 2000; Nadeau and Lewis-Beck, 2001; Duch and Stevenson, 2003; Listhaug, 2005). We already indicated that such interpretations are unconvincing when a single survey is analyzed, on account of the fact that variation between respondents cannot reflect a constant (i.e. the state of the economy at the time the survey was conducted). When pooling data from different surveys that are conducted in different economic circumstances, however, one could regard part of the variation in these assessments as a reflection of real economic circumstances (the remaining variation to be interpreted in different terms, possibly even as random). Seen from this perspective, subjective assessments of the economy are mediating variables that help to specify the causal mechanism by which the real economy affects government popularity and government vote shares.

The rivaling view maintains that subjective assessments of the economy are marred by endogeneity problems, implying that they are — at least in part caused by rather than causes of the variables that they were meant to explain: government support in one form or another. In case of endogeneity, estimated effects of the subjective economy on government support would be upwardly biased. Moreover, such bias would have spill-over effects on other coefficients in the same equation or in the same set of equations.

A third possibility would obviously be that the subjective economy does indeed mediate (part of) the effect of objective economic conditions on support for the government, while at the same time, also (endogenously) being caused by such support. This would involve a pattern of reciprocal causation that 
would limit, but not necessarily exclude the relevance of the subjective economy in individual-level explanatory models.

Confronted with these different views on the status of subjective economic evaluations, we will specify and test a series of causal models that differ from each other in these terms. One model represents the mediating variable perspective, a second represents the endogeneity perspective, and various other models represent different hybrid forms of mediation and endogeneity. These hybrid forms occasionally require non-recursive model specifications, in which subjective assessments of the economy and government support exert simultaneous causal effects on each other. A comparison of these models in terms of fit and parsimony will subsequently lead to a 'verdict' on the perspectives about the relevance of subjective assessments of the state of the economy.

\section{Data}

Our data come from the European Election Study 1999, a series of crosssection surveys fielded in all 15 countries of the European Union (EU) immediately after the elections to the European Parliament held in June 1999. ${ }^{7}$ Respondents from Northern Ireland were excluded from our analyses, because of the very small number of cases for that system, and because 'normal' patterns of credit and blame are not expected to operate in the same way in this context. Although the occasion for these surveys were the 1999 elections to the European Parliament, it is important to stress that the survey items used in our analyses do not relate to the European Parliament elections, but to the national political environments within the member countries. A further reason why we feel justified in using these data is that European Elections have been found to have the character of second-order national elections (Reif and Schmitt, 1980). This means that party choice in these elections is overwhelmingly motivated by factors that derive from the national political arena in each country. Other research (van der Eijk and Franklin, 1996; van der Eijk et al., 1996; Schmitt and Thomassen, 1999; van der Brug and van der Eijk, 2007) has shown that elections to the European Parliament do not provide stimuli that divert citizens from the substantive concerns that characterize their national political circumstances.

The surveys thus provide us with a total of 15 economic contexts across which to evaluate the relationship between objective economic indicators, subjective assessments of economic conditions and government support, providing considerable variation in terms of economic conditions. Levels of unemployment range from 2.8 to $16.4 \%$, declining in some, increasing in others. Inflation varies from a low of $0.3 \%$ to a high of $2.7 \%$, and growth in 
6

GDP from 1.0 to $8.6 \%{ }^{8}$ Differences between countries in terms of inflation are, perhaps, rather small to be picked up by differences in subjective assessments at the individual level; but, if such assessments do reflect differences in the real economy, we should see effects at least of growth and unemployment on subjective assessments.

Variance in real economic conditions can be obtained by pooling the surveys from the different political systems. These economic conditions for each country were imputed as variables to respondents from that country. When looking at the extant literature on economic voting, we find a variety of ways in which objective economic conditions are measured. Some focus on levels (of unemployment, wealth, etc.), others on changes (e.g. inflation, growth) and yet others on relative values of levels or changes (i.e. comparisons with other countries). A priori, none of these operationalizations can be dismissed as irrelevant; yet, it is obvious that each will yield different values, and that each of these will generate different patterns of multivariate relationships. In order not to risk capitalizing on the idiosyncrasies of a single particular operationalization, we conducted all analyses reported in this article for two different ways of measuring objective economic conditions. First, following Whitten and Palmer (1999), economic conditions were taken as deviations of unemployment, inflation and growth in GDP from the average of other relevant countries; in our case, all EU member countries. ${ }^{9}$ To complement these data, we used a set of measures employed by ourselves elsewhere (Van der Brug et al., 2007) in which economic conditions were measured in terms of changes over time within a single country (inflation, growth in GDP and change in unemployment). Although different in a number of details, the results from both sets of analyses concur with respect to the questions that are central to this article. Therefore, we feel justified in reporting the results of only the first of these operationalizations, which is the most widely used in the literature. ${ }^{10}$ For analytical purposes, the samples for each country are weighted to a uniform effective sample size (while keeping the effective $\mathrm{N}$ equal to the observed number of cases) so that different values for economic conditions contribute equally to the results.

From the surveys, we use three different variables. First of all, the subjective assessment of the economy is obtained from people's responses to the question: 'How about the state of the economy, how satisfied or dissatisfied are you with the current policy in 〈name of your country〉: are you very satisfied, somewhat satisfied, somewhat dissatisfied or very dissatisfied? ${ }^{11}$ With respect to 'dependent' variables in the tradition of economic voting, we use one variable for the $\mathrm{P}$-domain and one for the $\mathrm{V}$-domain. The first is provided by the question: 'Do you approve or disapprove of the government's record to date?' The indicator for the V-domain is: 'If there were <elections to your country's parliament $>$ tomorrow, which party would you vote for?', the 
responses to which were dichotomized into one category for government parties and one for opposition parties. Cases with incomplete information on any of these items were deleted, after which 7,206 cases remained for analysis.

\section{Design and Methods of Analysis}

To test and compare the different models, we need a method of analysis that is geared towards assessing the fit between a theoretically derived network of causal relationships on the one hand and empirically observed relationships between those variables on the other hand. The nature of the problem we address does not allow us to use some variant of regression analysis, as our main question is not to assess the total joint effect of a set of independent variables on a single dependent one. Rather, we deal with rivaling conceptions of the causal relations between a larger set of variables, among which the only causal effects whose direction is certain are those from (exogenous) objective economic conditions to individual-level variables in the models. ${ }^{12}$ To unravel the nature of the interrelations between these variables, we employ structural equation modeling, using LISREL (Bollen and Long, 1992; Jöreskog and Sörbom, 1993; Kline, 1998). ${ }^{13}$ We specify a set of structural models, estimate each and compare them in terms of fit and parsimony.

All the models contain only six variables: three objective economic indicators (pertaining to economic growth, inflation and unemployment), one variable measuring satisfaction with the economy, one measuring approval of the government and one indicating a vote for one of the parties in the incumbent government. It would have been preferable to use multiple indicators for the concepts represented in these models, as that would make it possible to integrate a measurement model and a structural model, thus estimating the causal relations at the level of latent variables (and accounting for random error variance in the manifest indicators). Lack of relevant additional indicators in the surveys prevents us from doing so; as a consequence we only estimate structural models between manifest variables. Yet, this lack of finesse is irrelevant for the purpose of determining the status of subjective economic assessments in relationship to other variables.

The limited number of variables included in our models may raise concerns about whether these models are underspecified. We disregard many of the most important variables in the field of electoral studies, such as partisanship, left/right ideology, cleavage-positions and so forth. These variables could not be omitted with impunity, if our object was to explain support for the government or subjective economic evaluations. But that is not our purpose. We are not interested in explaining voting behavior, but only in the question whether or not the alleged impact of objective economic conditions on voting 
behavior is (partially) mediated by subjective economic assessments. As none of these disregarded variables can sensibly be regarded to be causally antecedent to objective economic conditions, we need not control them in order to arrive at a valid answer to our central research question. ${ }^{14}$

As discussed above, our interest is to assess the relative merit of theories that differ from one another in terms of the causal ordering of the variables involved. This 'merit' can be expressed in measures of fit (or, conversely, of lack-of-fit) between an estimated model on the one hand and the empirically observed relationships between the variables on the other. Several such measures exist within the tradition of covariance structure analysis. Of these, we chose to use two, the root mean square error of approximation (RMSEA) and the chi-square statistic, which expresses the lack-of-fit between the empirically observed covariances on the one hand, and, on the other hand, the covariances that can be deduced from the optimally estimated parameters (under the assumption that the estimated coefficients are the true population values). ${ }^{15}$ Browne and Cudeck (1993) recommend on the basis of practical experience that one interpret an RMSEA of 0.05 or less as indicating a close fit of the model. Values of RMSEA larger than 0.10 would indicate models that were inadequate. Just as is the case for the RMSEA, lower chi-square values represent better-fitting models. An additional advantage of chi-square values is that they allow one not only to assess (lack of) fit, but also parsimony, expressed in terms of the degrees of freedom (df) (a larger $\mathrm{df}$ indicating a more parsimonious model). Even more importantly, in the case of nested models, the difference of their chi-square fit measures is itself chi-square distributed with the relevant $\mathrm{df}$ being given by differences in the $\mathrm{df}$ of the models being compared. This makes it possible to assess whether it pays off to increase (or diminish) the complexity of a model by adding (or deleting) causal effects. In the remainder of this paper, we are primarily interested in such comparisons of fit and parsimony. Obviously, the chi-square statistic of a model can also be used to test the null hypothesis, that discrepancies between observed and deduced covariance structures can be attributed to sampling variance. Models that survive this test can then be regarded as acceptable, whereas a rejection of this null hypothesis would require us to reject the causal theory specified in the model. This is not, however, our prime interest. The large number of cases (more than 7,200) and the obvious problem of omitted variables could easily result in artifactual rejection of perfectly acceptable models. ${ }^{16}$ However, irrespective of the acceptance or rejection of this null hypothesis, our approach does allow a valid comparison of different models and of the perspectives concerning the causal status of subjective economic evaluations specified in them.

In addition to the measures of fit and parsimony, the analyses also yield coefficients for the strengths of the causal effects specified in each of the 
models. We will comment upon these only occasionally, as the estimated value of many of these is not pertinent to our primary concern, which is to disambiguate causal relationships between the different variables.

\section{Findings}

The three types of models that we compare differ in the specified causal relations between the three individual-level variables: subjective economic assessments (satisfaction with the economy, indicated by $\mathrm{S}$ for schematic purposes in the illustrations that follow), a popularity variable (government approval, indicated by $\mathrm{P}$ ) and an electoral support variable (incumbent vote, indicated by V). We first briefly introduce each of these models and their fit. Subsequently, we will compare their relative merit.

\section{The conventional model: $\mathbf{S} \rightarrow \mathbf{P}$ and $\mathbf{S} \rightarrow \mathbf{V}$}

We will refer to our first model as the conventional model. It represents the mainstream of individual-level economic voting models in the literature. It is based on the idea that objective economic conditions are exogenous and impact on government support - popularity (P) and electoral support, or vote-choice (V) - via subjective economic evaluations. In this model, subjective assessments of the economy are caused by objective economic conditions, and constitute (one of the) cause(s) of government approval and electoral support. Obviously, this conventional model does not rule out the existence of direct effects of the real economy on $\mathrm{P}$ and $\mathrm{V}$. Moreover, subjective economic evaluations (S) can be influenced by other factors than the real economy. The defining characteristic in the conventional model is that subjective assessments of the economy mediate (part of) the causal influence of objective economic conditions on government support ( $\mathrm{P}$ and $\mathrm{V}$ ), and that they can thus be seen as elements in the causal mechanism that generates such support.

A model along these lines was specified and estimated using LISREL. As discussed earlier, the theoretical specification implies direct effects of the three objective economic conditions on each of the three individual-level variables (S, P and V). Whether all these permissible effects are necessary to acquire a reasonably fitting model is a matter for empirical analysis. In fact, we find consistently that inflation has no significant effect on the subjective economy (S), so that there is no need for the causal model to include that arrow. Equally consistently, we find the need to include a direct effect of inflation on voting for a government party (V) in order to arrive at an acceptable model. ${ }^{17}$ As this effect does not undermine the logic of the conventional model - in which subjective economic assessments are seen as mediating objective economic 


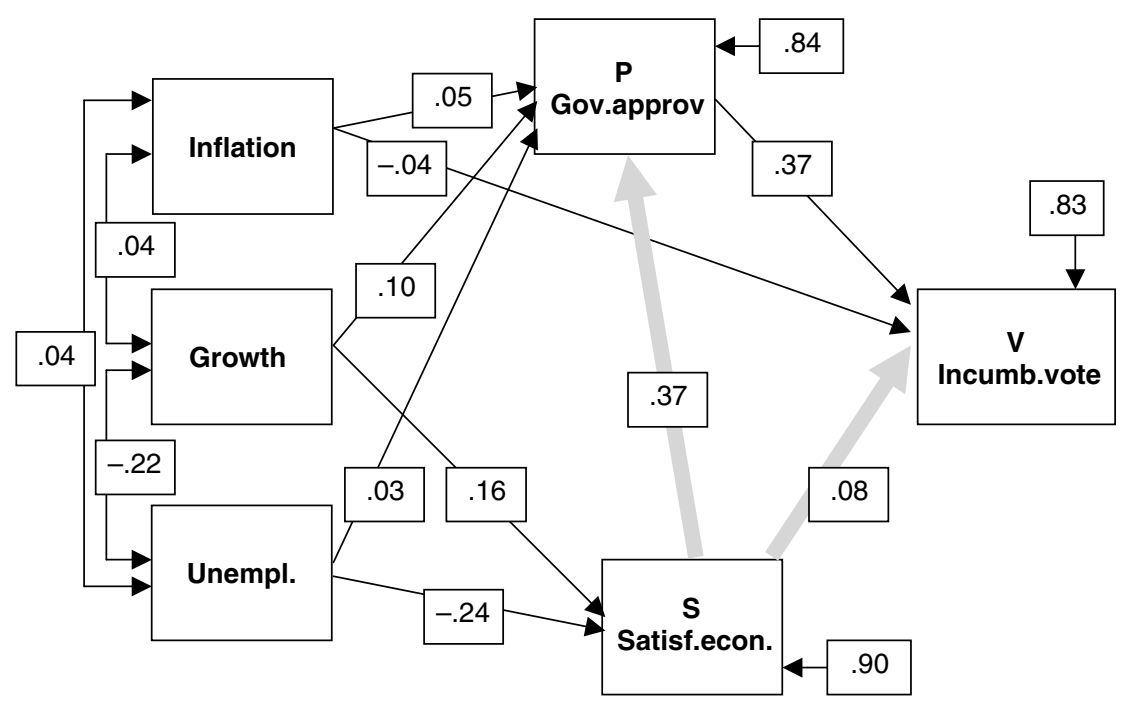

Figure 1 Conventional model: $\mathrm{S} \rightarrow \mathrm{P}$ and $\mathrm{S} \rightarrow \mathrm{V}$ (coefficients are standardized effect parameters). RMSEA $=0.022$. Chi-square $=15.55 ; \mathrm{df}=3 . p \leq 0.001$.

conditions - the inclusion of this effect does not compromise the classic perspective. In addition, the conventional model specifies direct effects of subjective economic assessments (S) on government support (P and V). Finally, an effect of government approval $(\mathrm{P})$ on electoral support for the government (V) can be expected. ${ }^{18}$ This model is graphically displayed in Figure 1; for ease of comparison, we emphasized in this visual representation, the two causal effects that distinguish this conventional model from its rivals. The value of the RMSEA (0.022) indicates that the model yields a quite acceptable fit, although the null hypothesis (which implies that lack-of-fit is of a magnitude compatible with sampling variation) must be rejected at the 0.01 level.

\section{The endogeneity model: $\mathbf{P} \rightarrow \mathbf{S}$ and $\mathrm{V} \rightarrow \mathrm{S}$}

This is the model that assumes endogenous effects from government support to economic assessments. According to the logic of the underlying argument, subjective assessments of the economy (S) are caused by government support $(\mathrm{P}$ and $\mathrm{V})$. In other words, a person is satisfied with the economy because, having no strong awareness of objective economic conditions or for whatever other reasons, (s)he employs a shortcut, or cue, and assesses the economy to be in good shape if (s)he approves of the government that is in charge of economic policy, or if (s)he has an electoral preference (expressed in voting) for an 


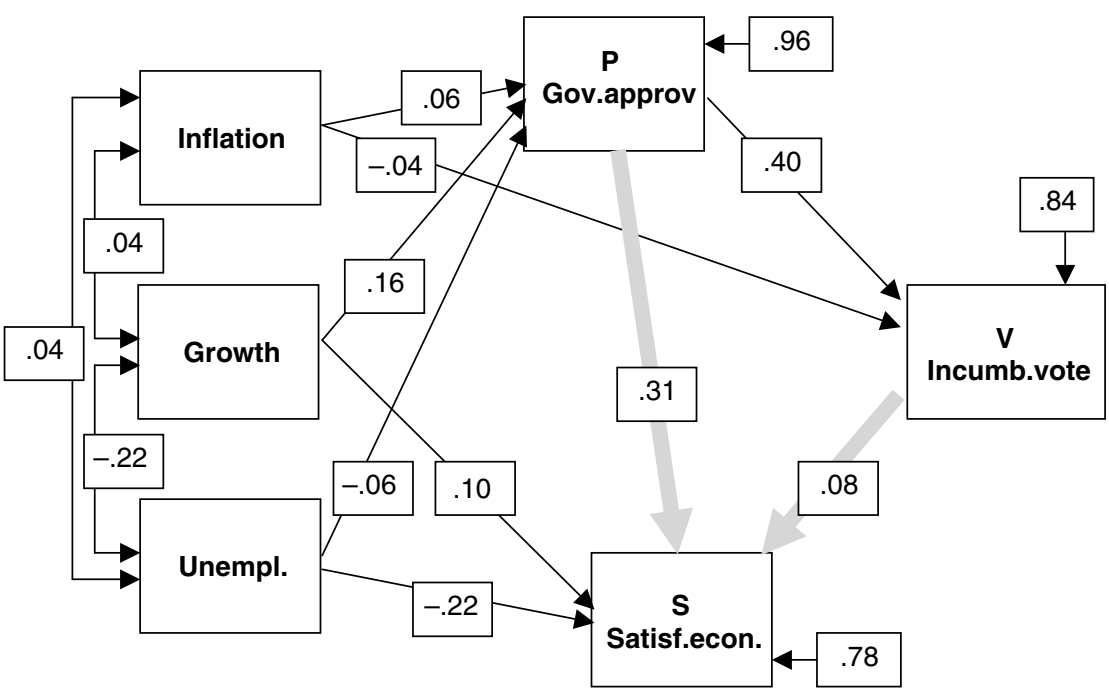

Figure 2 Endogeneity model: $\mathrm{P} \rightarrow \mathrm{S}$ and $\mathrm{V} \rightarrow \mathrm{S}$ (coefficients are standardized effect parameters). RMSEA $=0.015$. Chi-square $=8.59 ; \mathrm{df}=3 . p \leq 0.035$.

incumbent government party. In all other specifications, this model is identical to the conventional model. It has therefore the same df. It is schematically displayed in Figure 2.

With the same df, this model fits considerably better than the conventional model (as evidenced by lower values for RMSEA and chi-square). The lack-offit is so small that the null hypothesis - which states that lack-of-fit is caused by sampling variance - cannot be rejected even when using a significance level of 0.01 (which is a level that would be quite easy to attain, given the large number of cases on which the analysis is based). More elaborate comparisons between this model and the conventional model (and other models yet to be discussed) will be presented below.

\section{Hybrid models: partial endogeneity}

The two models just presented - the conventional model and the endogeneity model - can both be regarded as the ideal-type endpoints of a continuum with intermediate models in between. Such intermediate models would reflect $\mathrm{S}$ mediating the effects of the real economy on support for the government and simultaneously being endogenous to support for the government. In such hybrid models, subjective assessments of the economy are thus simultaneously cause and consequence of variables in the P-and V-domains. As we distinguish 


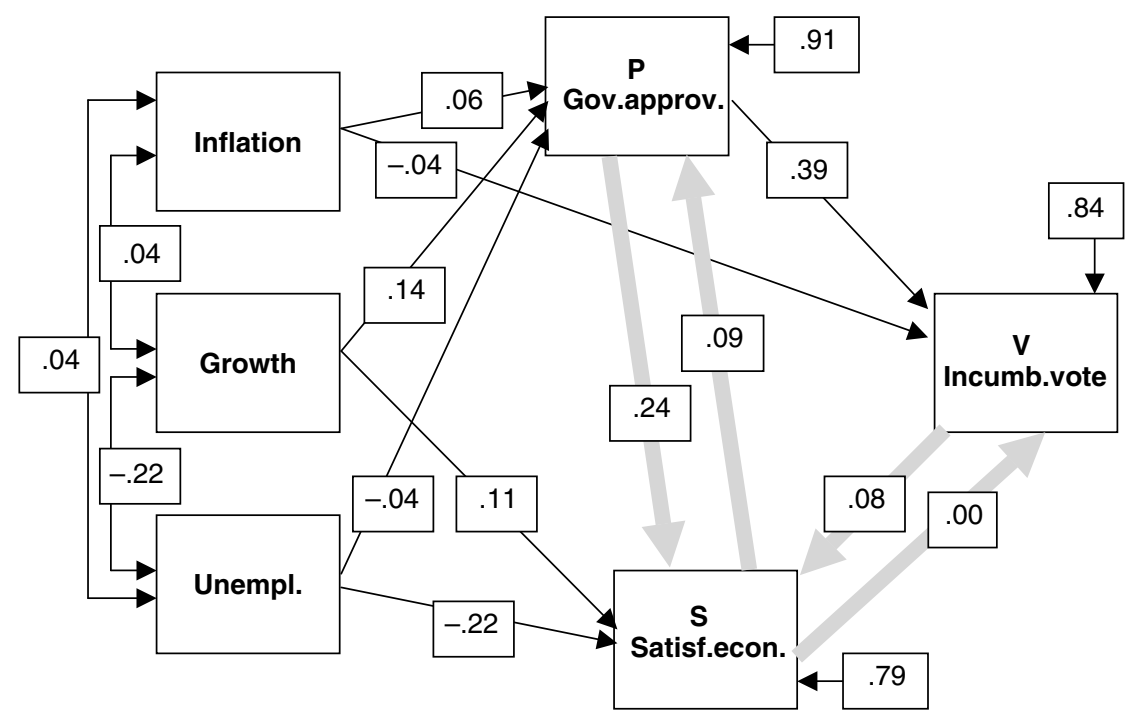

Figure 3 Hybrid model with two non-recursive effects: $\mathrm{S} \leftrightarrow \mathrm{P}$ and $\mathrm{S} \leftrightarrow \mathrm{V}$ (coefficients are standardized effect parameters). RMSEA $=0.029$. Chi-square $=8.36 ; \mathrm{df}=1 . p \leq 0.004$.

$\mathrm{P}$ and $\mathrm{V}$ as separate variables in our models, two different hybrid specifications are possible: V-endogeneity and P-endogeneity (endogeneity in both $\mathrm{V}$ and $\mathrm{P}$ would produce the endogeneity model reported in Figure 2). The specification with only $\mathrm{V}$-endogeneity would imply an indirect non-recursive aspect owing to the combination of the following effects: $\mathrm{P} \rightarrow \mathrm{V}, \mathrm{V} \rightarrow \mathrm{S}$ and $\mathrm{S} \rightarrow \mathrm{P}$. Nonrecursivity can, obviously, also be directly specified between $\mathrm{S}$ on the one hand and $\mathrm{P}$ and/or $\mathrm{V}$ on the other, which gives rise to three additional hybrid models: direct nonrecursivity with $\mathrm{V}$, with $\mathrm{P}$, or with both.

Rather than presenting all these possible hybrid models in detail, we present only one of them (see Figure 3) that contains direct non-recursive effects between $\mathrm{P}$ and $\mathrm{S}$, as well as between $\mathrm{V}$ and $\mathrm{S}$. This model is the most elaborate (least parsimonious) one that can still be estimated $(\mathrm{df}=1)$. Inspection of this specific model has the advantage that more parsimonious models (other hybrid models as well as the conventional model and the endogeneity model) are nested within it. This property implies that we can test for all models that are more parsimonious (reflected in higher df), whether or not the gains in parsimony result in significant worsening of fit. This hybrid model is entirely open-ended with respect to the causal status of the subjective economy, in contrast to the conventional and the endogeneity models. It may show that both perspectives are of roughly equal relevance, that either one of them is more important than the other, or that one of them is irrelevant. 
The information provided in Figure 3 shows, first of all, that the model fits reasonably well in terms of the values of RMSEA and chi-square. In spite of a marginally lower chi-square than the endogeneity model, the RMSEA is higher, which reflects the fact that this measure penalizes complexity that is not offset by better absolute fit. This is also reflected in the $p$-value of the chi-square, which indicates that the null hypothesis has to be rejected, or, in other words, lack-of-fit cannot be attributed to mere sampling variation. This is caused by the smaller number of $\mathrm{df}$ than in the other two models presented. When looking at the estimated coefficients, it is obvious that not all of the specified nonrecursivity reflects significant relationships between the variables. The estimated value of one of the reciprocal effects between $\mathrm{V}$ and $\mathrm{S}$ is virtually zero; more accurately, it is less than 0.005 , and the corresponding $t$-value of this coefficient is not significant at any sensible level, not even with over 7,200 observations. The reciprocal effects between $\mathrm{P}$ and $\mathrm{S}$ are of quite uneven value, although both are significant. Whether or not this reciprocal effect is worthwhile - in terms of the trade-off between fit and parsimony - cannot be determined just on the basis of the significance of individual parameters, however, but requires explicit testing of the significance of differences in fit between (nested) models. We will do this in the next section.

Substantively, the hybrid model reported in Figure 3 lends considerable support to the perspective that subjective assessments of the economy are not a cause of, but rather are caused by support for the government. Inspection of the reciprocal relationships shows that the effects representing endogeneity are very much stronger than their counterparts that run in the opposite direction.

\section{Comparing Alternative Models}

When investigating the causal status of the subjective economy in relation to government support (in its $\mathrm{P}$ - as well as in its $\mathrm{V}$-form), there are seven possible ways to specify a structural model. The conventional and endogeneity models are conceptually polar opposites. In between, we can distinguish two forms of partial endogeneity (P-endogeneity and V-endogeneity), and three models with reciprocal effects (reciprocity with $\mathrm{V}$, with $\mathrm{P}$ or with both). Three of these models have already been presented. Their major characteristics are summarized in Table 1, together with those of the other four models, which do not need to be presented in such detail.

When comparing the relevant information from these seven models, we may first consider their fit. In terms of the RMSEA criterion, all models fall well below the value of 0.05, which is suggested by Browne and Cudeck (1993) as boundary for acceptability. But that is of little help in deciding which one has the most merit. Model B (the endogeneity model) has the lowest RMSEA 


\begin{tabular}{|c|c|c|c|c|c|c|c|}
\hline & & $\begin{array}{l}\text { Relationship between } \\
\text { government support } \\
(P \text { and } V) \text { and } \\
\text { subjective economy }(S)\end{array}$ & RMSEA & Chi-Square & $d f$ & $p$ & $\begin{array}{l}\text { Direct and } \\
\text { total effects } \\
\text { of } S \rightarrow V\end{array}$ \\
\hline A & Conventional Model (see Figure 1) & $\begin{array}{l}\mathrm{S} \rightarrow \mathrm{P} \\
\mathrm{S} \rightarrow \mathrm{V}\end{array}$ & 0.022 & 15.55 & 3 & $\leq 0.001$ & $\begin{array}{l}0.08 \\
0.22\end{array}$ \\
\hline B & Endogeneity Model (see Figure 2) & $\begin{array}{l}\mathrm{P} \rightarrow \mathrm{S} \\
\mathrm{V} \rightarrow \mathrm{S}\end{array}$ & 0.015 & 8.59 & 3 & $\leq 0.035$ & $\begin{array}{l}\text { inap } \\
\text { inap }\end{array}$ \\
\hline $\mathrm{C}$ & Hybrid Model 1 (V-endogeneity) & $\begin{array}{l}\mathrm{S} \rightarrow \mathrm{P} \\
\mathrm{V} \rightarrow \mathrm{S}\end{array}$ & 0.017 & 10.33 & 3 & $\leq 0.016$ & $\begin{array}{l}\text { inap } \\
\text { inap }\end{array}$ \\
\hline D & Hybrid Model 2 (P-endogeneity) & $\begin{array}{l}\mathrm{P} \rightarrow \mathrm{S} \\
\mathrm{S} \rightarrow \mathrm{V}\end{array}$ & 0.020 & 12.96 & 3 & $\leq 0.005$ & $\begin{array}{l}0.08 \\
0.08\end{array}$ \\
\hline $\mathrm{E}$ & Non-recursive Model 1 & $\begin{array}{l}\mathrm{P} \rightarrow \mathrm{S} \\
\mathrm{V} \leftrightarrow \mathrm{S}\end{array}$ & 0.020 & 8.59 & 2 & $\leq 0.014$ & $\begin{array}{l}0.00 \\
\text { inap }\end{array}$ \\
\hline $\mathrm{F}$ & Non-recursive Model 2 & $\begin{array}{l}\mathrm{P} \leftrightarrow \mathrm{S} \\
\mathrm{V} \rightarrow \mathrm{S}\end{array}$ & 0.019 & 8.37 & 2 & $\leq 0.015$ & $\begin{array}{l}\text { inap } \\
\text { inap }\end{array}$ \\
\hline $\mathrm{G}$ & Non-recursive Model 3 (see Figure 3) & $\begin{array}{l}\mathrm{P} \leftrightarrow \mathrm{S} \\
\mathrm{V} \leftrightarrow \mathrm{S}\end{array}$ & 0.029 & 8.36 & 1 & $\leq 0.004$ & $\begin{array}{l}0.00 \\
\text { inap }\end{array}$ \\
\hline
\end{tabular}

Columns represent structural characteristics, residual mean square error of approximation (RMSEA), Chi-square fit, degrees of freedom (df) and probability under the null-hypothesis, and the standardized effects of subjective economy on vote choice. 
value, but the differences between the models are small and statistically ambiguous. ${ }^{19}$ When using chi-square as a criterion to test the null-hypothesis that deviation from perfect fit is due to sampling variation (rather than to a misspecification of the model), we find four models with an acceptable fit: models $\mathrm{B}, \mathrm{C}, \mathrm{E}$ and $\mathrm{F}$ (for these $p>0.01$ ). These values of RMSEA and chi-square thus clearly illustrate the well-known phenomenon that an acceptable fit is at best a necessary, not a sufficient condition for its acceptance, as other models, based on different theoretical considerations, may also acceptably fit the same empirical observations.

When trying to assess the relative merit of the various nested models, chisquare is of more use than RMSEA (or most of the other fit measures used in the literature). Each of the models $\mathrm{A}$ to $\mathrm{D}$ is nested in one of the models $\mathrm{E}, \mathrm{F}$ and $\mathrm{G}$ (and $\mathrm{A}$ to $\mathrm{F}$ are all nested in $\mathrm{G}$ ). The relevance (or, costeffectiveness) of a more detailed model can be assessed when that model is compared with a simpler one in which it is nested, by testing the significance of the difference of their chi-square values (with df defined by the difference of the df's of the models to be compared). When comparing, for example, Model G with Model F (in which it is nested), we see that their difference is the $\mathrm{S} \rightarrow \mathrm{V}$ effect (which is included in $\mathrm{G}$ but not in $\mathrm{F}$ ). This difference in model specification yields a difference in chi-square values of $0.01(8.37-8.36)$ with one df (2-1). At no reasonable criterion is such a small improvement in chi-square significant at $\mathrm{df}=1$. In other words, Model $\mathrm{F}$ should be preferred over model G. On a similar basis, can we compare Models G and E and conclude that the cost (in terms of $\mathrm{df}$ ) of including $\mathrm{S} \rightarrow \mathrm{P}$ in the model are not earned back in terms of reduction of chi-square. In conjunction, this implies that there is no reason to model either of these two effects, which reduces Models $\mathrm{E}, \mathrm{F}$ and $\mathrm{G}$ to Model $\mathrm{B}$, the endogeneity model. Having discarded in this way Models E, F and G as irrelevant (using $p \leq 0.01$ as a criterion), two models remain: $\mathrm{B}$ and $\mathrm{C}$. These two models have in common that the subjective economy is modeled as endogenously influenced by vote choice. In terms of fit, model $\mathrm{B}$ is to be preferred over Model C, owing to a lower chi-square value at the same level of parsimony (df), but this difference is not significant. ${ }^{20}$ There is an additional reason for preferring Model B over Model C. Model B is simpler than Model C because it does not contain the indirect nonrecursivity that we commented upon earlier $(\mathrm{S} \rightarrow \mathrm{P}, \mathrm{P} \rightarrow \mathrm{V}$ and $\mathrm{V} \rightarrow \mathrm{S})$.

What about the conventional model? Apart from the fact that it has the worst fit of all these models, it is telling that any adaptation that brings in elements of endogeneity improves the fit in terms of absolute chi-square value (from Model A via C and D to B). Conversely, when elements of the conventional model are added to the endogeneity model by way of nonrecursive effects, we find that this has only costs (in terms of df) without gains 
(in terms of less significant chi-square values). In short: there is very little empirical support for any of the defining elements of the conventional model. ${ }^{21}$

\section{Conclusions, Implications and Discussion}

What do our analyses add up to? First, with respect to our main substantive question, we have to conclude that the 'subjective economy' cannot in any shape or form contribute to the explanation of government support, irrespective of whether that support is expressed in the popularity domain (as is the case with government approval) or electorally. Subjective assessments of the economy are not cause of but rather caused by government support, as is abundantly clear from our comparative assessment of all possible models. Without comparison of different models, one could easily be misled, however. The conventional model fits quite reasonably (in terms of RMSEA), and would lead one to conclude that subjective assessments of the economy have quite substantial effects on voting for government parties (estimates of such effects are indicated in the final column of Table 1). ${ }^{22}$ Yet, such a conclusion would not be warranted in view of the significantly better fit of the theoretically rivaling endogeneity model (whose low chi-square assures us that the small discrepancies between this model and the data could well be the result of chance, quite in contrast to the conventional model).

When using other methods of analysis, it is even more difficult to detect the pitfalls of the conventional model. In all kinds of regression approaches - still very much the favorite method of analysis in the economic voting literature the use of the subjective economy as predictor for government support will yield coefficients that will be interpreted as (causal) effects. This interpretation is only correct, however, to the extent that the assumption is justified that the independent variables are not themselves influenced by the dependent one, and that assumption itself cannot be tested in the regression approach. Structural equation models are able to test the validity of that assumption, which in this instance leads to a resounding rejection. This finding bodes ill for much of the individual-level tradition in the economic voting literature that is based on subjective measures of the economy. As we stated at the start of this article, such usage is problematic anyway in the context of a single survey on account of the fact that the variation of responses cannot reflect variations in real economic conditions between respondents (there is no such real variation). But although pooling subjective economic assessments over different economic contexts does solve this problem, we still do not find the subjective economy functioning as an individual-level link between the real economy and government support. 
This finding is not caused by the subjective economy being unrelated to the real one. On the contrary, in each of our models, we found that objective economic conditions (both growth and unemployment) ${ }^{23}$ exert significant and interpretable effects on subjective assessments of the economy (however, most of these effects are rather weak, see the coefficients reported in the diagrams of Figures 1-3). This finding may also put to rest doubts that could be raised over the somewhat unusual formulation of our subjective economy item (see footnote 11). If this item would not have tapped subjective assessments of the economy, there would have been no reason for it to be directly affected by real economic conditions. The double-barreled formulation of the item did not lead to the effects of the objective economy being entirely mediated by government approval, in which case, the validity of the item as belonging to the subjective economy domain would have been suspect. Unusual as the item's formulation may be, our use of it as an indicator of the subjective economy seems to be vindicated by the results of our analyses.

The inability of the subjective economy to link objective economic conditions to government support implies that further research is necessary to pry open this black box at the level of individual voters. This is essential for two reasons. The first one is that voting is above all an individual act, and analyses at the aggregate level are therefore inherently in danger of aggregation artefacts. Only individual-level analyses can satisfactorily underpin the major conclusions from aggregate-level analyses. Our analyses have contributed to this by demonstrating that the real economy certainly does matter at the level of individual voters and that it does affect vote choices. It does so, however, not by way of subjective assessments of the economy but by way of government approval (not surprisingly, better economic conditions lead to higher government approval).

The second reason why further research is needed is because our elaboration of the causal mechanism is substantively rather poor. Linking the real economy to individual voting via government approval is not tautological, but the explanation is conceptually too close to the dependent variable to be entirely satisfactory.

Nevertheless, our findings in this article have demonstrated that individuallevel analyses cannot be built on subjective assessments of the economy, as the mediator between real economic conditions and government support. A next item on the agenda for further research is to differentiate between contexts in more ways than only objective economic conditions. Powell and Whitten (1993) demonstrated that countries differ in the clarity of responsibility for (economic) policies, and that this difference is of consequence for voter behavior. Van der Brug et al. (2007) also find that the way in which economic conditions impact electoral choice is affected by this aspect of the context in 
which voters find themselves. These findings do not logically imply that the causal status of the subjective economy differs between contexts, yet such differences cannot be ruled out. In the present context, the limited variation of economic conditions precluded us from pursuing these possibilities; however, doing so would require more contexts and, preferably, greater variation between them in economic conditions.

Our probing of the black box that links objective economic conditions to voters' support for the government (either in its popularity/approval form or in terms of electoral support) has yielded more negative findings than positive ones. We have been able to falsify the notion that the causal mechanism involves subjective economic assessments, but we have not been able to specify the causal mechanism in a positive way. In order to pry the black box open, it is obvious that we need to marshal additional empirical information. We have to assess other variables, in terms of their possible role in linking the real economy to voters' support for the government, in order to make certain that findings at the aggregate level are not artefacts. ${ }^{24}$ Moreover, additional information is needed in order to escape from the somewhat flat-footed way in which the research problem has until now been conceptualized in the economic voting literature (a conceptualization that we respected in this article in order to connect our findings to the existing literature). Traditionally, the dependent variable in economic voting studies has been defined as support for the government, either in terms of popularity or in terms of voting. But the relevance of this perspective is essentially limited to the relatively small number of countries where single-party government is the normal state of affairs. Most democracies are governed by coalitions, and voters' choices at the ballot box are cast for political parties, not for governments. In such systems, vote choice cannot be plausibly construed as support for the government (or lack thereof). It is rare to find popularity or vote shares of coalition partners moving in step. It is much more common that some members of the coalition lose votes while other governing parties gain. The same goes for the major opposition parties in a multi-party system. Some of these may 'benefit' from a slow economy, but others do not. It therefore seems necessary to focus not primarily on how the economy affects support for governments the virtually exclusive focus in the economic voting literature - but rather how the economy affects support for individual parties. In view of the divergent fortunes of individual parties, it is obvious that individual parties' characteristics have to be taken into account when answering that question (see Van der Brug et al., 2007). But even then, the findings of the analyses, presented in this article, council against using the subjective economy as part of the causal mechanism that links real economic conditions to individual parties' political fortunes. 


\section{References}

Bartels, L.M. (1996) 'Uninformed votes: information effects in presidential elections', American Journal of Political Science 40: 194-230.

Bollen, K.A. and Long, J.S. (eds.) (1992) Testing Structural Equation Models, Beverley Hills, CA: Sage.

Browne, M.W. and Cudeck, R. (1993) 'Alternative ways of assessing model fit', in K.A. Bollen and J.S. Long (eds.) Testing Structural Equation Models, Beverley Hills, CA: Sage, pp. 136-162.

van der Brug, W. and van der Eijk, C. (eds.) (2007) European Elections and Domestic Politics. Lessons from the Past and Scenarios for the Future, Notre Dame: University of Notre Dame Press.

Van der Brug, W., van der Eijk, C. and Franklin, M. (2007) The Economy and the Vote, Cambridge MA: Cambridge University Press.

Chrystal, K.A. and Alt, J.E. (1981) 'Some problems in formulating and testing a politico-economic model of the United Kingdom', The Economic Journal 91: 730-736.

Dorussen, H. and Taylor, M. (eds.) (2002) Economic Voting, London: Routledge.

Duch, R.M. and Palmer, H.D. (2002) 'Heterogeneous perceptions of economic conditions in crossnational perspective', in H. Dorussen and M. Taylor (eds.) Economic Voting, London: Routledge, pp. 139-172.

Duch, R.M. and Stevenson, R. (2003) 'Re-evaluating economic voting', Paper presented at the Joint Sessions of Workshops ECPR, Edinburgh.

van der Eijk, C. and Franklin, M. (1996) Choosing Europe? The European Electorate and National Politics in the Face of Union, Ann Arbor: University of Michigan Press.

van der Eijk, C., Franklin, M. and Marsh, M. (1996) 'What voters teach us about Europe-wide elections; what Europe-wide elections teach us about voters', Electoral Studies 15: 149-166.

Erikson, R.S. (1989) 'Economic conditions and the presidential vote', American Political Science Review 83: 567-573.

Fair, R. (1988) 'The effect of economic events on the vote for president: a 1984 update', Political Behavior 10: 168-179.

Fiorina, M.P. (1981) Retrospective Voting in American National Elections, New Haven, CT: Yale University Press.

Franklin, M., Mackie, T. and Valen, H. et al. (1992) Electoral Change: Responses to Evolving Social and Attitudinal Structures in Western Countries, Cambridge: Cambridge University Press.

Hibbs, D.A. (1982) 'On demand for economic outcomes: macroeconomic performance and mass political support in the United States, Great Britain and Germany', Journal of Politics 44: 426-462.

Jöreskog, K.G. and Sörbom, D. (1993) Lisrel 8, Hillsdale, NJ: Scientific Software International.

Kinder, D.R. and Kiewiet, D.R. (1979) 'Economic discontent and political behavior: the role of personal grievances and collective economic judgments in congressional voting', American Journal of Political Science 23: 495-527.

Kline, R.B. (1998) Principles and Practice of Structural Equation Modeling, New York: Guildford Press.

Kramer, G. (1983) 'The ecological fallacy revisited: aggregate-versus individual-level findings on economics and elections, and sociotropic voting', American Political Science Review 77: 92-111.

Lewis-Beck, M.S. (1988) Economics and Elections: The Major Western Democracies, Ann Arbor: University of Michigan Press.

Lewis-Beck, M.S. and Paldam, M. (2000) 'Economic voting: an introduction’, Electoral Studies 19: $113-122$.

Listhaug, O. (2005) 'Retrospective voting', in J.J.A. Thomassen (ed.) The European Voter A Comparative Study of Modern Democracies, Oxford: Oxford University Press, pp. 213-234. 
MacKuen, M.B., Erikson, R.S. and Stimson, J.A. (1992) 'Peasants or bankers? The American Electorate and the U.S. Economy', American Political Science Review 86: 597-611.

Markus, G.B. (1988) 'The impact of personal and national economic conditions on the presidential vote: a pooled cross-sectional analysis', American Journal of Political Science 32: 137-154.

Markus, G.B. (1992) 'The impact of personal and national economic conditions on presidential voting, 1956-1988 (in update)', American Journal of Political Science 36: 829-834.

Middendorp, C.P. and Kolkhuis Tanke, P.R. (1990) 'Economic voting in the Netherlands', European Journal of Political Research 18(5): 535-555.

Nadeau, R. and Lewis-Beck, M.S. (2001) 'National economic voting in US presidential elections', Journal of Politics 63: 159-181.

Nannestad, P. and Paldam, M. (1997) 'The grievance asymmetry revisited: a micro study of economic voting in Denmark, 1986-1992', European Journal of Political Economy 13: 81-99.

Nannestad, P. and Paldam, M. (2000) 'Into Pandora's Box of economic evaluations: a study of the Danish macro VP function, 1986-1997', Electoral Studies 19: 123-140.

Paldam, M. and Nannestad, P. (2000) 'What do voters know about the economy? A study of Danish data, 1990-1993', Electoral Studies 19: 363-392.

Powell Jr, G.B. and Whitten, B.G. (1993) 'A cross-national analysis of economic voting: taking account of the political context', American Journal of Political Science 37: 391-414.

Reif, K. and Schmitt, H. (1980) 'Nine second-order national elections. a conceptual framework for the analysis of European election results', European Journal for Political Research 8: 3-44.

Schmitt, H. and Thomassen, J. (eds.) (1999) Political Representation and Legitimacy in the European Union, Oxford: Oxford University Press.

Thomassen, J. (ed.) (2005) The European Voter, Oxford: Oxford University Press.

Tufte, E. (1976) Political Control of the Economy, Princeton, NJ: Princeton University Press.

Whitten, G. and Palmer, H.D. (1999) 'Cross-national analyses of economic voting', Electoral Studies 18: 49-67.

Wlezien, C., Franklin, M. and Twiggs, D. (1997) 'Economic perceptions and vote choice: disentangling the endogeneity', Political Behavior 19: 7-17.

Zaller, J.R. (2005) 'Floating voters in U.S. presidential elections 1948-2000', in W.E. Saris and P.M. Sniderman (eds.) Studies in Public Opinion: Attitudes, Nonattitudes, Measurement Error, and Change, Princeton: Princeton University Press.

\section{Notes}

1 Earlier versions were presented at the Annual Meeting of the Dutch Political Science Association ('Politicologendagen'), Noordwijk, 23-24 May 2002, and at the Workshop on 'Perceptions, Preferences and Rationalization: Overcoming the Problem of Causal Inference in the Study of Voting', Nuffield College, Oxford, 7-9 May 2004. We are indebted to the participants in those meetings for their comments and criticisms.

2 See Time International, vol. 140, no. 44, 2 November 1992, p. 38.

3 The results of this line of research are much less stable or consistent, cf. Lewis-Beck and Paldam, 2000, 114; Dorussen and Taylor, 2002, 1.

4 One could, of course, argue that economic conditions vary between individuals, and that the conceptualization of 'the' economy (in the singular) obfuscates this. When seen from that perspective, overall levels of unemployment, inflation and growth are irrelevant, and the consistent aggregate-level findings that the economy affects support for governments can only be an artefact. Yet, this position is not shared at all in the economic voting literature, which focuses expressly on 
'the' economy, which is, therefore, not an individual-level phenomenon in itself but a contextual one that, at any given time, takes on the same values for all citizens in a country.

5 Even when different surveys include items about the same concepts, variations in the formulation and format of survey questions often prevent pooling of surveys into a single dataset. These comparability problems can be quite severe, as can be seen in the comparative studies coordinated by Franklin et al. (1992) (where the solution was sought in dichotomizing all variables, thus discarding much empirical information) and by Thomassen (2005) (where the solution chosen was to discard entire surveys from the analyses, when comparability was insufficient).

6 Such subjective assessments of the state of the economy are among the standard items included in most contemporary national election studies.

7 The survey was conducted by telephone interviewing. The numbers of realized interviews varied between the EU member countries, with some 1,000 respondents interviewed in Denmark, France, Germany, the Netherlands, Spain and the United Kingdom, and some 500 interviews in the remaining countries except Luxembourg and Italy. In Luxembourg, 300 interviews were felt to be sufficient. In Italy, the questionnaire was administered by a telepanel and some 3,700 interviews were realized. The study was funded largely by the Dutch National Science Foundation and the University of Amsterdam, with important additional contributions from the CIS (Madrid), the University of Mannheim and Trinity College, Connecticut. The studies are available for secondary analysis from Steinmetz Archives (Amsterdam), the ICPSR at the University of Michigan and from various European data archives. The studies are extensively documented on the European Elections Studies Web Site (http://www.europeanelectionstudies. net). This site not only describes the surveys, but also contains an extensive list of publications emanating from these studies.

8 Our data about the objective state of the economies of these systems are obtained from Eurostat/OECD.

9 Whitten and Palmer $(1999,52)$ follow Powell and Whitten $(1993,392)$ in using deviations from the average for all industrialized democracies, arguing that politicians can attack or defend economic performance in the light of international comparisons. Our choice of only the EU as baseline makes no substantive difference to our findings, but is politically more relevant in the countries we study.

10 We ourselves prefer the second operationalization, but our objective here is to provide a critique of the extant literature. A full report of the results based on the second operationalization can be obtained from the first author.

11 The formulation of this item differs somewhat from the most usual ones that are used in the economic voting literature, but we consider it as similar to more conventional items about retrospective evaluations of the economy (the reference to 'current' policies is irrelevant in this respect). The item is even to some extent double barreled, combining a (subjective) assessment of economic conditions with an (equally subjective) evaluation of government policy. Unfortunately, it is the only suitable measure available to us in this otherwise uniquely suitable dataset. Yet, as we will discuss in the concluding section, the findings from our analyses vindicate our interpretation of this item as tapping (retrospective) subjective assessments of the economy. Our data do not contain indicators or proxies for prospective subjective measures of economic.

12 The causal ordering between objective economic indicators and individual-level variables cannot be changed, in spite of the fact that it is quite plausible that, collectively, individual assessments of the economy, and the behavior generated by them, do affect objective economic conditions in the long run. At any given moment in time, however, individuals (as observed in our surveys) are not able to influence the economy.

13 All models are estimated from covariances. 
14 It is conceivable that subjective economic evaluations might be affected by these variables; in which case our estimates of the effects between government support (approval or vote) and subjective economic evaluations might be overestimated without, however, altering the comparisons of the effects between these variables.

15 We refrain here from reporting other measures of fit, as they do not provide additional information that is of relevance in the context of the research question addressed here.

16 Note that levels of significance employed in these tests might appear back to front, in terms of normal usage. In order to have confidence in rejecting the null hypothesis that lack of fit results from sampling variance, we need low levels of probability. In view of the large $N$, we will only reject $\mathrm{H} 0$ when $p<0.01$.

17 These findings also hold for the alternative operationalization of objective economic conditions, discussed earlier.

18 The reverse ordering between government approval and voting for one of the government parties seems unlikely on theoretical grounds. Moreover, exploratory LISREL analyses demonstrated that reversing the causal direction between these two variables does not yield a satisfactory fit.

19 The $95 \%$ and even the $99 \%$ confidence intervals of the RMSEA values of the various models (not separately presented here) all overlap, which makes any decision as to which of the models has most merit, statistically ambiguous in terms of RMSEA.

20 There is a second reason for preferring Model B over Model C. Model B is simpler than Model $\mathrm{C}$ in a way that is not reflected in df. Model $\mathrm{C}$ contains an indirect nonrecursivity that we commented upon earlier $(\mathrm{S} \rightarrow \mathrm{P}, \mathrm{P} \rightarrow \mathrm{V}$ and $\mathrm{V} \rightarrow \mathrm{S})$. This element is missing in Model $\mathrm{B}$, which is thus more parsimonious.

21 When using our alternative definition of objective economic conditions (see footnote 9), we equally find that the endogeneity fits better than the conventional model or any hybrid. In that set of analyses, we find, however, roughly, equally strong non-recursive effects between $\mathrm{S}$ and $\mathrm{P}$ (from $\mathrm{S}$ to $\mathrm{P}$ and from $\mathrm{P}$ to $\mathrm{S}$ ). In combination with effects from $\mathrm{P}$ to $\mathrm{V}$ and from $\mathrm{V}$ to $\mathrm{S}$ (from $\mathrm{S}$ to $\mathrm{V}$ is not significant, when estimating nonrecursivity between $\mathrm{S}$ and $\mathrm{V}$ ), this yields a positive feedback cycle between $\mathrm{P}, \mathrm{V}$ and $\mathrm{S}$. Readers interested in the full set of analyses using the alternative operationalization of objective economic conditions may obtain these from the first author.

22 The entry 'inap' is inserted in Table 1 when there is no direct or indirect causal path from $\mathrm{S}$ to $\mathrm{V}$, or when the calculation of total effects is ambiguous owing to indirect nonrecursivity.

$23 \mathrm{We}$ do not find effects of inflation on subjective economic assessments, but there is no compelling need for all economic conditions to have a direct effect on these assessments.

24 Such analyses require variation across economic contexts, and thus pooling across surveys. Only recently, has such an approach become feasible due to the advent of highly comparable survey data generated by projects such as the European Elections Studies (EES), the European Social Survey (ESS) and the Comparative Study of Electoral Systems (CSES) project (see van der Brug et al., 2007) for an example of the use of such data. 